\section{Relationship between Oxalate Concentration and Leaf Position in Various Spinach Cultivars}

\author{
I. Okutani and N. Sugiyama ${ }^{1}$ \\ Faculty of Agriculture, University of Tokyo, Bunkyo-ku, Tokyo 113, Japan
}

Additional index words. Spinacia oleracea, plastochron

Abstract. A negative relationship has been reported between the oxalate concentration in leaves and leaf position numbered from the base for 'Okame' spinach (Spinacia oleracea L.). We compared changes in leaf and stem oxalate concentrations among three cultivars. 'Viroflay' differentiated and developed leaves at a lower rate than did 'Okame' and 'Kyoho'. Oxalate concentrations in plant tops decreased with time in 'Okame' and 'Kyoho', but 'Viroflay' changed little. The relationship between leaf oxalate concentration (Y; millimoles per gram of fresh weight) and its position on the stem $(X)$ was the same for all cultivars and can be given as $Y=-0.0089 X+0.158$.

Because the excessive intake of oxalate interferes with $\mathrm{Ca}$ adsorption in the digestive tract, spinach's high oxalate level is the main problem associated with its use as food (Libert and Franceschi, 1987). Genetic variations in spinach oxalate content have been reported (Doesburg and Zweede, 1948; Eheart and Massey, 1962; Kitchen et al., 1964; Yoshikawa et al., 1988; Yukura and Hongo, 1963), but breeding spinach with a low oxalate content has not been successful. Hirooka and Sugiyama (1992) found that, with time, patterns of changes in oxalate concentration in spinach tops differed among cultivars. However, each leaf showed a constant oxalate concentration as it grew, and the higher the leaf position from the plant base, the lower the oxalate concentration (Okutani and Sugiyama, 1992). Our purpose was to ascertain whether the relationship between leaf oxalate concentration and leaf position differed among cultivars.

\section{Materials and Methods}

'Okame', 'Kyoho', and 'Viroflay' spinach seeds (purchased from Takii Seed Co., Kyoto, Japan) were germinated and sown on 19 Sept. 1991. On 2 Oct., when cotyledons were fully developed, four seedlings each were transplanted to containers filled with 8 liters of nutrient solution. Thirty-five containers were allotted to each cultivar. Nutrient solution, initially at $\mathrm{pH} 6$, was composed of (mM) 4 $\mathrm{NaNO}_{3}, 1 \mathrm{KH}_{2} \mathrm{PO}_{4}, 0.5 \mathrm{~K}_{2} \mathrm{SO}_{4}, 2 \mathrm{CaCl}_{2}$, and 1 $\mathrm{MgSO}_{4}$ and $53.9 \mu \mathrm{M}$ Fe-ethylenediamine tetraacetic acid (EDTA) and Hoagland's trace elements (Hoagland and Arnon, 1950). The solution was renewed every 4 days. Leaves were numbered upward from the lowest leaf, excluding cotyledons.

Received for publication 8 June 1993. Accepted for publication 10 May 1994. The cost of publishing this paper was defrayed in part by the payment of page charges. Under postal regulations, this paper therefore must be hereby marked advertisement solely to indicate this fact.

${ }^{1}$ To whom reprint requests should be addressed.
Starting on 8 Oct. (day 0), plants in five containers were harvested at 4-day intervals when leaf 5 reached $1 \mathrm{~cm}$ in length. Leaves of $+0.003, r^{2}=0.990$. Vertical bars represent SE. cultivars. ${ }^{\mathrm{z}}$ Equation: $\mathrm{Y}=\mathrm{aX}+\mathrm{b}$. experiment. four plants from each container were harvested; those at each leaf position were combined and weighed. At the final sampling (day 16), 'Okame' and 'Kyoho' leaves from positions 4 to 10 and 'Viroflay' leaves from positions 4 to 9 were frozen in liquid $\mathrm{N}_{2}$. In addition, plants in five other containers with roots removed were sampled on day 0 and day 16 , and they also were immediately frozen in liquid $\mathrm{N}_{2}$ for determining oxalate concentrations in plant tops. Frozen tissues were homogenized with $2 \mathrm{~N} \mathrm{HCl}$ at $1 \mathrm{ml} \cdot \mathrm{g}^{-1}$ with a mortar and pestle; then, the homogenate was transferred to a volumetric flask with additional $1 \mathrm{~N} \mathrm{HCl}$. The filtrate of each extract was injected into a high-pressure liquid chromatography system equipped with an analytical column for organic acids (model HPX $87 \mathrm{H}$; BioRad, Richmond, Calif.). The mobile phase was $0.008 \mathrm{~N} \mathrm{H}_{2} \mathrm{SO}_{4}$, and the flow rate was 0.6 $\mathrm{ml} \cdot \mathrm{min}^{-1}$ at $35 \mathrm{C}$. The change in absorbance was monitored at $210 \mathrm{~nm}$ with an ultraviolet detector. The oxalate concentration for each leaf or plant without roots was expressed on a fresh weight basis. Data were evaluated by regression procedures.

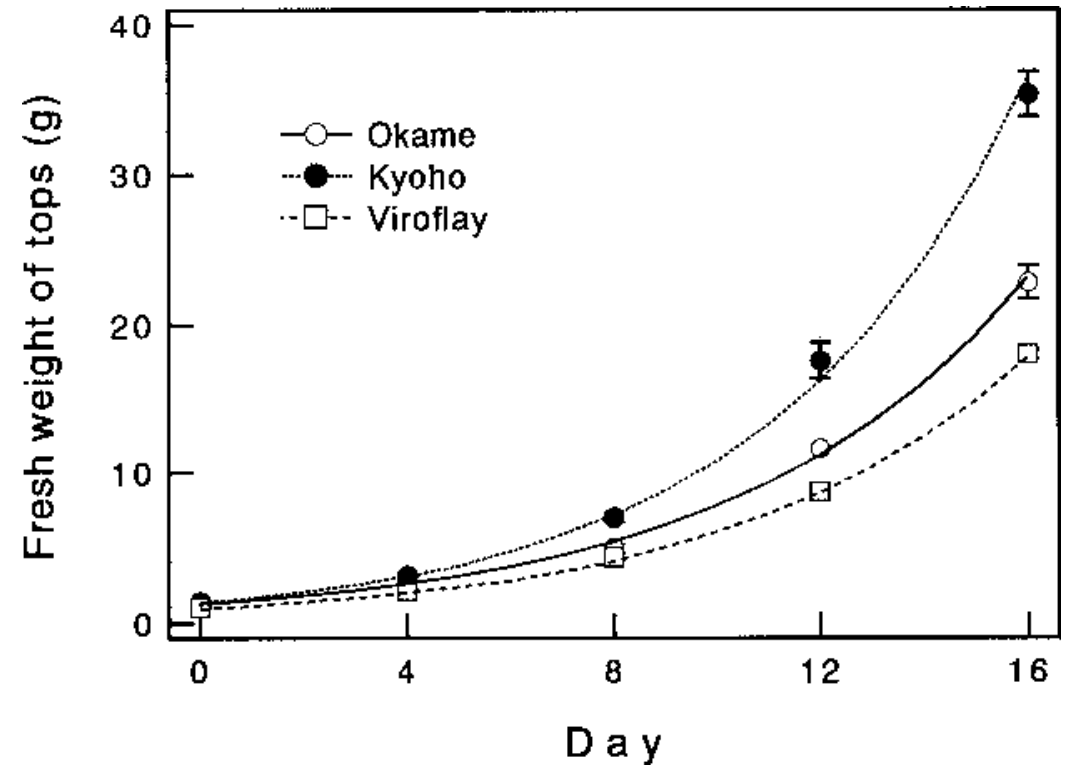

Fig. 1. Changes in plant-top fresh weights during the experiment with three spinach cultivars. Plants were harvested at 4-day intervals from 8 Oct. (day 0). The regression equations are as follows: 'Okame', In $\mathrm{Y}=0.183 \mathrm{X}+0.207, r^{2}=0.994$; 'Kyoho', $\ln \mathrm{Y}=0.203 \mathrm{X}+0.352, r^{2}=0.992$; and 'Viroflay', $\ln \mathrm{Y}=0.180 \mathrm{X}$

Table 1. Regression coefficients (a) for leaf fresh weight in grams $(\mathrm{Y})$ in relation to time $(\mathrm{X})$ (days counting from 8 Oct.) and regression constants (b) for individual leaves at each leaf position for three spinach

\begin{tabular}{|c|c|c|c|c|c|c|}
\hline \multirow{3}{*}{$\begin{array}{l}\text { Leaf } \\
\text { position }\end{array}$} & \multicolumn{6}{|c|}{ Cultivars } \\
\hline & \multicolumn{2}{|c|}{ Okame } & \multicolumn{2}{|c|}{ Kyoho } & \multicolumn{2}{|c|}{ Viroflay } \\
\hline & a & b & a & b & $\mathrm{a}$ & b \\
\hline 4 & 0.152 & 0.132 & 0.196 & 0.363 & 0.150 & -0.059 \\
\hline 5 & 0.192 & -0.277 & 0.287 & -0.482 & 0.201 & -0.486 \\
\hline 6 & 0.255 & -1.148 & 0.377 & -1.660 & 0.282 & -1.553 \\
\hline 7 & 0.237 & -1.300 & 0.412 & -2.295 & 0.305 & -2.596 \\
\hline 8 & 0.285 & -2.326 & 0.530 & -4.413 & 0.188 & -1.641 \\
\hline 9 & 0.216 & -1.849 & 0.354 & -3.096 & 0.128 & -1.472 \\
\hline 10 & 0.256 & -2.866 & 0.459 & -5.268 & $---y^{\prime}$ & --- \\
\hline
\end{tabular}

${ }^{2}$ Correlation coefficients $(r)$ for all relationships were significant at $P \leq 0.01$.

'Regression coefficients could not be calculated for leaf 10 of 'Viroflay' because it developed late in the 


\section{Results and Discussion}

Plant fresh weights increased exponentially with time (Fig. 1). The relative growth rate of 'Kyoho' plants $\left(0.203{\left.\mathrm{~g} \cdot \mathrm{g}^{-1} \cdot \text { day }^{-1}\right) \text { was }}\right.$ higher than that of 'Okame' $\left(0.183 \mathrm{~g} \cdot \mathrm{g}^{-1} \cdot \mathrm{day}^{-1}\right)$ or 'Viroflay' plants $\left(0.180 \mathrm{~g} \cdot \mathrm{g}^{-1} \cdot \mathrm{day}^{-1}\right)$. Fresh weights of individual leaves increased linearly with time, and relationships between leaf weight and time were highly significant (Table 1). The time at which fresh weight was zero was obtained by extrapolation from these regression lines to provide an estimate of the dates on which each leaf began to develop. Leaves started to develop at a constant interval, and the period between the start of development of two successive leaves (i.e., the plastochron) was a little longer for 'Viroflay' than for 'Okame' and 'Kyoho' (Fig. 2). Thus, 'Okame' and 'Kyoho' had developed 13 leaves by day 16, and 'Viroflay' had developed 12 . The plastochron index ' $n$ ' is defined as the developmental stage of a plant at which leaf ' $\mathrm{n}$ ' begins to enlarge (Erickson and Michelini, 1957); therefore, our leaf counts approximate the plastochron index of the plant at day 16 .

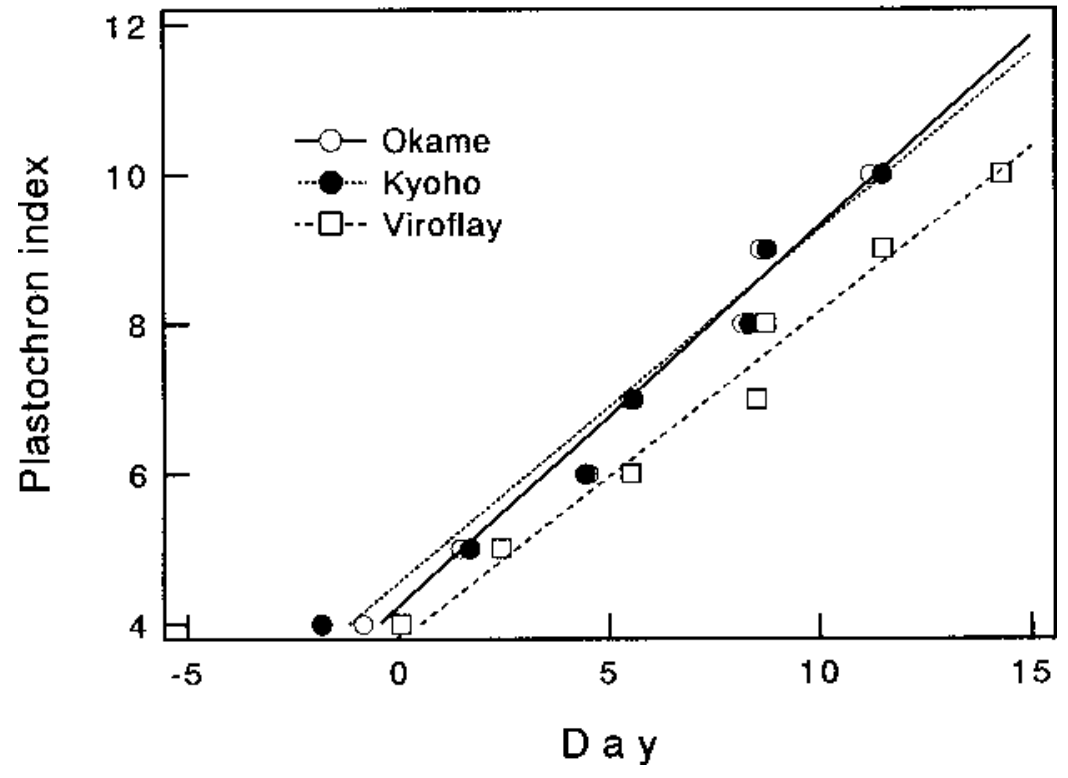

Fig. 2. Plastochron index as a function of time for three spinach cultivars. The plastochron index ' $n$ ' is defined as the developmental stage of the plant at which leaf ' $n$ ' begins to enlarge. Day 0 was 8 Oct. The regression equations are as follows: 'Okame', $\mathrm{Y}=0.506 \mathrm{X}+4.22, r=0.99$; 'Kyoho', $\mathrm{Y}=0.490 \mathrm{X}+4.27$, $r=0.99$; and 'Viroflay', $\mathrm{Y}=0.438 \mathrm{X}+3.79, r=0.99$.

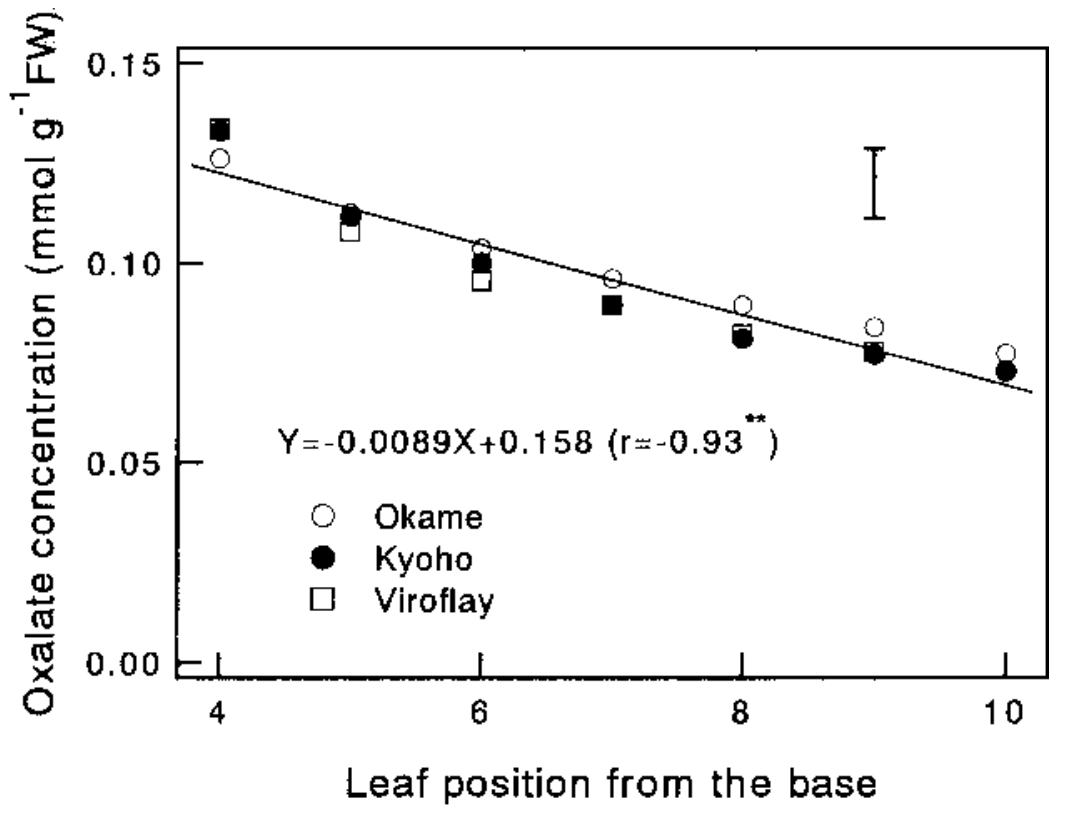

Fig. 3. The relationship between leaf oxalate concentration and leaf position for three spinach cultivars. The regression line was calculated using pooled data from all three cultivars. Vertical bar represents LSD.
Table 2. Oxalate concentrations in plant tops (mmol/ $\mathrm{g}$ fresh weight) on day 0 and on day 16 for three spinach cultivars.

\begin{tabular}{lcc}
\hline \hline Cultivars & Day 0 & Day 16 \\
\hline Okame & $0.109 \pm 0.003^{z}$ & $0.092 \pm 0.008$ \\
Kyoho & $0.113 \pm 0.003$ & $0.091 \pm 0.002$ \\
Viroflay & $0.119 \pm 0.001$ & $0.116 \pm 0.006$ \\
\hline
\end{tabular}

${ }^{\mathrm{z}}$ Means $\pm \mathrm{SE}, \mathrm{n}=5$.

Individual leaf oxalate concentrations decreased as the leaf position increased (Fig. 3). The relationship between the oxalate concentration and leaf position was significant for each cultivar, and parameters for the regression lines were similar for the cultivars. Therefore, oxalate concentrations in individual leaves of the three cultivars could be described by the same equation: $\mathrm{Y}=-0.0089 \mathrm{X}+0.158(r=$ $\left.-0.93^{* *}\right)$, where $\mathrm{Y}$ is the oxalate concentration (in millimoles per gram of fresh weight) in leaf $\mathrm{X}$, numbered from the base.

The oxalate concentration in plants decreased from day 0 to day 16 (Table 2). Daily rates of decreases in plant oxalate concentrations differed among cultivars; the lowest being for 'Viroflay' and the highest for 'Kyoho'. Because oxalate concentrations in each specific leaf remained constant during its development (Okutani and Sugiyama, 1992) and leaf oxalate concentrations decreased at a constant rate as leaf position increased for all three cultivars (Fig. 3), the faster leaf development resulted in lower plant oxalate concentrations. Indeed, 'Kyoho', which showed a greater decrease in the plant oxalate concentration with time, had a shorter plastochron. Therefore, a short plastochron, which means many leaves at harvest, seems to be associated with a low oxalate concentration in spinach leaves at harvest. The involvement of the plastochron in controlling plant oxalate concentrations seems quite plausible because Yukura and Hongo (1963) found a genetic correlation between the number of leaves and the oxalate concentration in spinach tops. From the perspective of controlling the oxalate concentration in spinach plants, it is important to note that a varietal difference was found in the plastochron. This varietal difference stands in marked contrast to plant oxalate concentrations at the seedling stage, which barely differ among cultivars (Yoshikawa et al., 1988). Our results suggest that the oxalate concentration in each leaf is not an important consideration in breeding spinach cultivars with a low oxalate content.

\section{Literature Cited}

Doesburg, J.J. and A.K. Zweede. 1948. Oxalic-acid, calcium, ascorbic acid and dry matter content of some spinach strains (in Dutch with English and French summaries). Voeding 9:12-25. (Hort. Abstr. 18:2688,1948.)

Eheart, J.F. and P.H. Massey, Jr. 1962. Factors affecting the oxalate content of spinach. J. Agr. Food Chem. 10(6):325-327.

Erickson, R.O. and F.J. Michelini. 1957. The plastochron index. Amer. J. Bot. 44:297-305.

Hirooka, M. and N. Sugiyama. 1992. Effect of growth rates on oxalate concentrations in spin- 
ach leaves (in Japanese with English summary). J. Jpn. Soc. Hort. Sci. 61(3):575-579.

Hoagland, D.R. and D.I. Arnon. 1950. The water culture method for growing plants without soil. Calif. Agr. Expt. Sta. Circ. 347.

Kitchen, J.W., E.E. Burns, and P.A. Perry. 1964. Calcium oxalate content of spinach (Spinacia oleracea L.). Proc. Amer. Soc. Hort. Sci. 84:441-445.
Libert, B. and V.R. Franceschi. 1987. Oxalate in crop plants. J. Agr. Food Chem. 35(6):926938.

Okutani, I. and N. Sugiyama. 1992. Oxalate concentration in spinach leaves during ontogenesis. HortScience 27:642. (Abstr.)

Yoshikawa, T., K. Nakagawa, T. Kobayashi, S. Tokieda, and K. Nagai. 1988. Studies on high- quality production and shipment of spinach. I. Effects of varieties and growth stage on oxalic acid content (in Japanese). Kinki Chugoku Agr. Res. 75:71-76.

Yukura, Y. and I. Hongo. 1963. Effectiveness of selection of oxalic acid content in spinach (in Japanese with English summary). Bul. Faculty Agr. Tamagawa Univ. 4:19-29. 